\title{
The doctor in the twenty first century
}

\author{
ASTRID NØKLEBYE HEIBERG
}

To look into the future entails extrapolating from present knowledge with the awareness that this process may lead us into the wilderness. Nevertheless, I believe that today's two great trends will continue into the twenty first century-namely, growth and differentiation.

To consider growth first; in the twenty first century there will still be a growing gap between the demand for health care and society's ability to pay for it out of public funds. Though today health care costs take an ever increasing part of every European country's gross national product, the pressure for improvement is even more rapid. There are three main sources of these pressures. Firstly, the vast number of new possibilities for diagnosis and treatment, produced by developments in gene technology, immunology, transplantation, and radiology. Secondly, the aging of our population with the increased demands for maintenance and care. Thirdly, the family's diminished capacity for caring for the elderly, both because of the necessity for mobility and because the traditional unpaid caretaker (the daughter or daughter in law) now works outside the home: caring for the very young, the sick, and the disabled has thus become a public responsibility.

My second trend, differentiation, is an even more complex topic. The number of people working in the health sector is now four or five times what it was at the end of the second world war. The number of professions within the health services has trebled-probably few of us could list all the subgroups within the professions. Today's hospital has come to resemble an airport, with a stream of different people-entertaining for the young man with the broken leg, but devastating for the confused old lady.

We also have the struggle between the professions for money, power, and influence, as well as the struggles between different departments and faculties. Given that any willingness to change priorities in budgets or allocations of rooms may be interpreted as a sign of weakness, every responsible member of the health service is now a warrior defending his or her patients, profession, or colleagues. New challenges are inevitably met by new demands for resources-as shown by the fight against AIDS. We all come to bang our heads against the low ceiling of cash limits, and all of us get a headache.

At present no less than $70 \%$ of all money devoted to health care is spent on the last six months of life. Less than $10 \%$ is spent on health promotion, whatever our adherence to the gospel of "prevention is better than cure." As always, the chronically ill and the mentally retarded come at the end of the queue.

But priorities are maintained not only through tradition: they also arise through public demand and the formidable combined force of the public and the press-and the lawyers. We do not have to cup our ears to hear the voice of public dissatisfaction; rather we have to shield them against the deafening roar. The pedestal that doctors used to occupy at social gatherings has been replaced by a tight corner where they are trapped by people with triumphant smiles telling of the wonderful cures with homoeopathy, the laying on of hands, ginseng, ying yang, or whatever. And our medical educators are found to be guilty of promoting a course of instruction which is too mechanical, technical, fragmented, and hospital orientated. In the public eye the doctor should take on entirely new roles.

But should he? Is the old Aesculapian oath obsolete? Are we no longer to cure disease, alleviate pain, or both? Indeed, we are; we could also add the promotion of health and still be within the old framework. Today's problem is more that medicine has become too much of a science and too little of a service-the ability to make a diagnosis and the compassion and skill to cure.

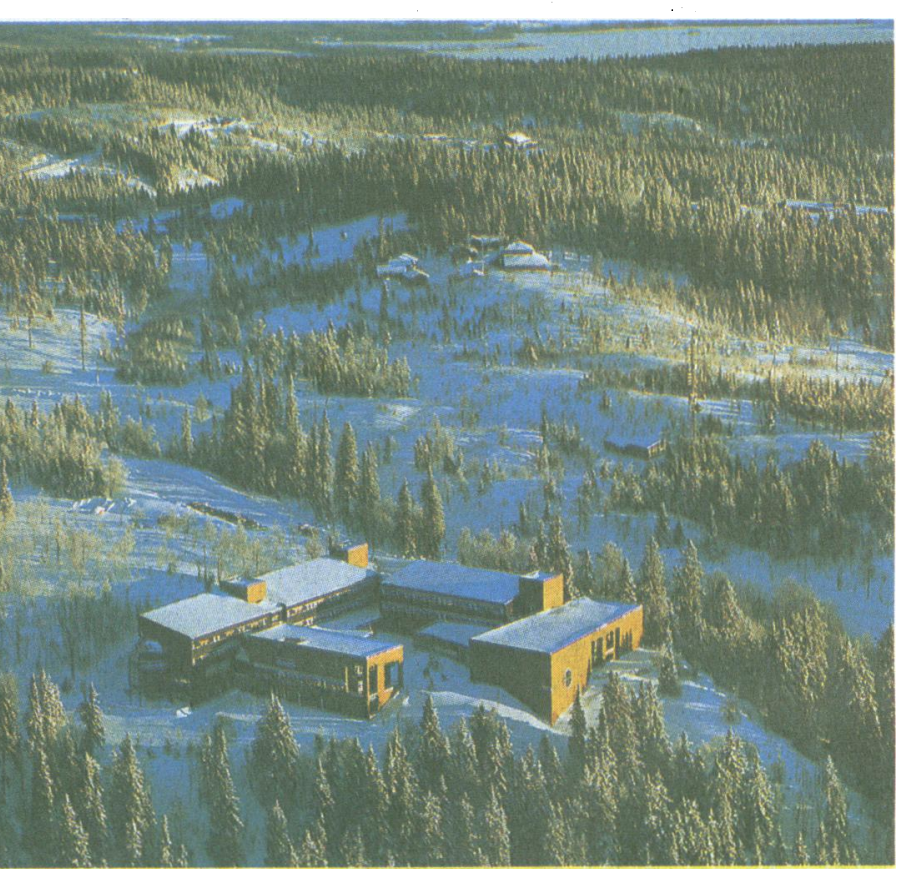

Soria Moria, Oslo, conference centre of the Norwegian Medical Association.

\section{Still fantastic doctors around}

Given my gloomy start, let us change the viewpoint. There are still fantastic doctors around. What are they like?

The patient's description would be simple: they can detect signals of serious disease in time; they are trustworthy, available, and good listeners. Nothing more. These are the demands of today's patients, and they will probably assume even greater importance for future ones, the elderly women who present in outpatients with a variety of symptoms and ailments.

One of my colleagues is carrying out research into the needs of such patients, starting with the hypothesis that the doctor and the patient communicate on different levels. Could it be that the dialogue is more like that in the plays of Becket and Ionesco, so that the patient is often given stones instead of bread? No doubt the doctor may diagnose a urinary infection, a raised blood pressure, or mild anaemia. She will be given the correct treatment and leavebut is this the help she came for?

My colleague does not have the answer yet, but she has now come to pose a different question from the usual one: "Well, what is the matter with us today?" Instead, she asks: "What would you most of all want me to do for you today?" And she gets new answers-such as: "Do you think my blood could start clogging my veins?" Or: "My real worry is that my daughter may be an alcoholic." The answers speak of anxiety and uncertainty, while revealing the world 
we doctors normally shy away from-the world of silly fears and thoughts, of strange, often animistic ideas, and of a stunning lack of knowledge about what the body looks like and how it functions. But this is the reality in which our patients live, far away from our clear view of anatomy and our sophisticated measurements of biological processes. As our instruments develop-and indeed they do and will continue to evolve-persons without a detectable deficiency will become rarer and rarer, especially if they are elderly. Such developments will enhance the difference between illness and disease and patients will be treated for more and more diseases (and probably "cured") while their true pain is not dealt with. The answer to their real problem is listening, communication, mutuality.

What sort of fantastic doctor do we want for society? That is a more complicated question. Society demands that the doctor should be efficient. He should use his resources so as not to distort the economic framework while he serves his patients' needs. For example, a hospital superintendent or the head of a group practice has to be a good administrator, ensuring that the most costly part of the organisation - the personnel-work as smoothly and effectively as possible. It also means that he has to be aware of the cost of new apparatus and should not insist that only his special interests should be accommodated. (I have visited several hospital attics, where discarded machinery stands around under covers like tombstones over the special interests of the passing professors.) It also means that he has to be flexible in changing work routines from their emphasis on inpatients to one on outpatients, while respecting that patients' time is valuable and that they have a right to be kept informed.

Most doctors I know think that this way of working is what they would naturally, happily, do were they not obstructed by incompetent bureaucracy, by superfluous and obsolete laws and regulations, and by cowardice and weakness on the part of politicians who back off from making the necessary decisions. Probably they are right. So the next question is: how do you deal with bureaucrats and politicians? Beat them or join them? Some of us join them.

\section{Strategies for health promotion}

Society expects the doctor not only to combat disease, but also to promote health, in its widest sense. Of the several strategies to do this - optimally in the setting of primary health care-the first aims at improving lifestyle. The doctor's task is to make people aware of risk factors in their lifestyle, smoking, alcohol consumption, physical fitness, eating habits-to repeat the key words. The goal is simple. But changing people's behaviour is very difficult. What little we know about the process of change indicates that campaigns often have only a passing effect. What works is direct, personal, tailor made information which hits you personally. The general practitioner has to focus on and train for his forceful position as an educator. Most medical curriculums do not provide such training.

Another health promoting strategy is the wider one of primary and secondary prevention of disease. The obvious cornerstones here are cleaning up the environment, ensuring healthy conditions for food production, screening special health risk groups, rehabilitating disabled people, and promoting safety everywhere from sex to transport and working conditions. Here is the grey zone between medicine and other realms of society where the medical component probably accounts for only $10 \%$ of the possible benefits.

But also in our health care system we have to redefine our priorities. A lot of work is still going on in outmoded routines which were meaningful long ago when they were introduced. Surely today, for instance, it is sheer nonsense to measure the height and weight of all schoolchildren instead of concentrating on those who clearly need more attention to their psychological needs.

A third strategy is to bring about a fairer and a juster distribution of our health services. New and fascinating medical treatments, and the patients who are their hosts, find their way into curriculums, wards, and budgets. Not so the less exciting patients, in whom treatment is either banal or inefficient, progress small, and gains dubious. There is the ever present load of chronic sick, the mentally retarded, and the senile- or just ordinary old people. Numerically these form a large group; their needs and sufferings are great; they always get a mention in speeches and plans; yet they are virtually non-existent in curriculums, practical teaching, and research programmes. Up to the present our research workers have mostly been men. But, with the current gradual increase in female research workers, the focus may shift in future and new priorities emerge. Whether that will create a better balance or a greater imbalance in medicine in general remains to be seen.

I have briefly considered the demands for service made on doctors by patients and society. What about the coworkers? "The doctor I work with is fantastic," said my friend the nurse the other day, and I asked "Why?" "Because we feel safe when he is there," she replied. "We know that if he cannot do anything for the patient nobody else can either. And he is available. He even comes when he is off duty to follow up if that is needed." Most of us, I believe, identify with this description. This is how we felt when we were first year students: doctors should be able, trustworthy, and dedicated to their patients. If they were like this we could accept grumpiness, strange habits; and harsh demands-even lack of democratic behaviour. In the breaking down of the hierarchical structure in the hospital, in the promotion of cooperation, team work, and group responsibility, we have sometimes lost this attitude of dedication to work with patients. A hospital has become less of a treatment place for the sick and more of a working place for the healthy. Group meetings, education, and information may all take up so much time and energy that we lose contact with the patients. Then the work itself becomes meaningless.

To recapitulate the basic requirements, a doctor should be knowledgeable, capable of assigning priorities, skilful, dedicated, trustworthy, available, flexible, a good listener, a good teacher, a good leader, a good health promoter, and a life long student and researcher. As a spokesperson for society, I fear that the biggest obstacle against reaching that goal is the doctor's own power base: the existing medical faculties, the present structure, and the present merit system "both for student and for teachers. Just as in psychotherapy, the existing systems can be changed only through a combination of inner and outer pressures. The inner pressure is there through the demands for change that we are all so well aware of. The outer pressure can be achieved by a consensus on a new approach to medical education. If such a consensus can be reached the next step will be to determine how this could be implemented and what sort of surveillance and help we could give to one another. In this we shall need the benefits of good behaviour reinforcement and gratification, and strong, enduring support and understanding in the long phase of working through.

Department of Psychiatry, University of Oslo, Oslo, Norway

ASTRID NØKLEBYE HEIBERG, MD, professor of psychiatry, member of the Norwegian Parliament

Based on an address given at Sovia Moria, Oslo, on 11 September 1987 at a symposium in honour of Dr Ole Harlem, editor of the Norwegian Medical fournal.

Correspondence to: Stortinget, Høyres Stortingsgruppe, 0026 Oslo 1, Norway. 